WellBeing International

WBI Studies Repository

2013

\title{
Humane Society International's Global Campaign to End Animal Testing
}

Troy Seidle

Humane Society International

Follow this and additional works at: https://www.wellbeingintlstudiesrepository.org/acwp_arte

Part of the Bioethics and Medical Ethics Commons, Laboratory and Basic Science Research Commons, and the Politics and Social Change Commons

\section{Recommended Citation}

Seidle, T. (2013). Humane Society International's global campaign to end animal testing. Alternatives to laboratory animals: ATLA, 41(6), 453-459.

This material is brought to you for free and open access by WellBeing International. It has been accepted for inclusion by an authorized administrator of the WBI Studies Repository. For more information, please contact wbisr-info@wellbeingintl.org.

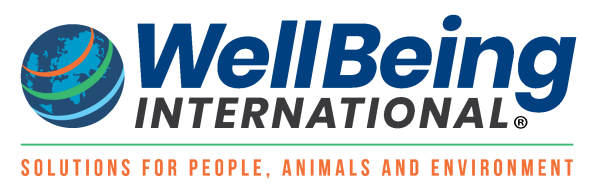




\title{
Humane Society International's Global Campaign to End Animal Testing
}

\author{
Troy Seidlea
}

Research \& Toxicology Department, Humane Society International, Toronto, ON, Canada

\begin{abstract}
Summary - The Research \& Toxicology Department of Humane Society International (HSI) operates a multifaceted and science-driven global programme aimed at ending the use of animals in toxicity testing and research. The key strategic objectives include: a) ending cosmetics animal testing worldwide, via the multinational Be Cruelty-Free campaign; b) achieving near-term reductions in animal testing requirements through revision of product sector regulations; and c) advancing humane science by exposing failing animal models of human disease and shifting science funding toward human biology-based research and testing tools fit for the 21st century. HSI was instrumental in ensuring the implementation of the March 2013 European sales ban for newly animal-tested cosmetics, in achieving the June 2013 cosmetics animal testing ban in India as well as major cosmetics regulatory policy shifts in China and South Korea, and in securing precedent-setting reductions in in vivo data requirements for pesticides in the EU through the revision of biocides and plant protection product regulations, among others. HSI is currently working to export these life-saving measures to more than a dozen industrial and emerging economies.
\end{abstract}

Key words: adverse outcome pathway, animal testing, AXLR8, chemical, cosmetic, data requirements, Horizon 2020, HSI, Human Toxicology Project, OECD, pesticide, REACH, regulatory alignment, Three $R$ best practices.

Address for correspondence: Troy Seidle, Humane Society International, 506-460 Sainte Catherine Ouest, Montréal, QC H3B 1A7, Canada.

E-mail: tseidle@hsi.org

\section{Introduction}

Humane Society International (HSI), and its affiliates, together constitute one of the world's largest and most effective forces for animal protection. HSI is widely respected as an authority on animal research and testing issues, and is frequently called upon by governments, corporations and other official bodies for its advice and expert opinion. Its team of scientists, policy experts, campaign professionals, investigators and supporters spans the globe, acting as a voice for humane and human-relevant testing and research that moves beyond outdated animal models by using the most advanced tools that 21 st century science has to offer.

\section{HSI Strategy and Accomplishments}

\section{Be Cruelty-Free: Ending cosmetics animal testing worldwide}

HSI played a leading role in driving European institutions to follow through on their commitment to ban the sale of newly animal-tested cosmetics, which became effective on 11 March 2013. Years of high-level political negotiations were coupled with high-profile public campaigning — including recruitment of top celebrity supporters such as Sir Paul McCartney, Leona Lewis, Ricky Gervais and many others, and a corporate partnership with Lush cosmetics, through which hundreds of thousands of petition signatures were collected in mere weeks - to achieve the celebrated victory: a Europe free from cosmetics animal cruelty. Yet so long as powerful emerging markets such as China continue to require animal testing, not only for new cosmetic ingredients, but also for each new product formulation (1), HSI's efforts could not remain limited to Europe.

Be Cruelty-Free was born from the recognition that the global nature of the cosmetics industry, coupled with differing regional regulatory requirements (2), necessitated a coordinated, multinational strategy, if a worldwide end to animal testing for cosmetics was to be achieved. In April 2012, HSI and its affiliates, in partnership with Lush and animal protection groups in Australia, Brazil, Canada, India, Korea, New Zealand, Russia and the USA, launched Be Cruelty-Free, with the goal of making cruelty-free cosmetics the global mainstream by replicating the European animal testing and sales bans across all 
key global cosmetics markets. A global online pledge was launched at hsi.org/becrueltyfree and in more than 700 Lush shops in 48 countries, to educate consumers and provide them with an avenue to support the campaign. Be Cruelty-Free has since expanded also into China, Japan and Taiwan, for a total of 12 concurrent regional campaigns (Figure 1).

A partial list of Be Cruelty-Free's achievements to date include the following:

- In India, being instrumental in convincing policymakers to delete the last remaining animal tests from the country's cosmetics standard (3), thereby effectively banning cosmetics testing involving animals. Today, HSI-India is holding top-level meetings with Government officials to achieve an extension of the ban to prohibit also the sale of cosmetics that have been subject to new animal testing in other parts of the world.

- In Brazil, influencing the revision of national cosmetics safety assessment guidelines, which were updated following an HSI workshop in December 2012, and now provide for acceptance of all Three $\mathrm{Rs}$ test guidelines promulgated by the Organisation for Economic Co-operation and Development (OECD; 4). In September 2013, HSI filed a regulatory proposal with Brazil's Conselho Nacional de Controle de Experimentação Animal (CONCEA) calling for a national cosmetics animal testing ban, with the backing of more than 150 Brazilian federal parliamentarians.

- In China, HSI and the Humane Society of the United States (HSUS) have awarded an $\$ 80,000$ grant to the Institute for In Vitro Sciences (IIVS) to provide hands-on training to government regulators, and academia and industry scientists, on the use and interpretation of non-animal OECD test guideline methods. In previous years, HSI has co-funded similar IIVS training courses for Brazilian and Russian stakeholders. Since the launch of $B e$ Cruelty-Free in China, the China Food and Drug Administration has announced the first revision of the country's cosmetics framework regulation in 20 years.

- In South Korea, intensive political, regulatory and corporate engagement prompted the Ministry of Food and Drug Safety to announce a significant policy shift to formally recognise non-animal test results for assuring the safety of sunscreens, anti-wrinkle creams and other 'functional' cosmetics. Additionally, the government has committed to invest 166 billion Won (approx. \$145 million) to establish Korea's first Centre for Alternatives to Animal Testing.

- In New Zealand, HSI delivered a similar submission to the Parliament, as it reviews the country's Animal Welfare Act. HSI and our NZ campaign partner have also launched a national advertising campaign calling for Kiwi Prime Minister John Key to 'hop to it' and ban animal testing for cosmetics (Figure 2).

HSI and its partners are also working to influence new and revised laws and regulations governing the trade and testing of chemicals (similar to the Europe's Registration, Evaluation, Authorisation and Restriction of Chemicals [REACH] system, discussed further below) to prevent the creation of loopholes that would allow, or even require, new animal testing for cosmetic raw ingredients. In many parts of the world, Be Cruelty-Free has put the animal testing issue on the public policy agenda for the very first time. Yet, from the Americas to Asia and Oceania, opinion polls funded by HSI and its partners have revealed unprecedented levels of public support for nationwide bans on cosmetics animal testing (5), and $B e$ Cruelty-Free is helping to drive public policy discussions in Brazil, China, New Zealand, South Korea and beyond, with first-of-their-kind legislative proposals arguing the case for cosmetics animal testing bans.

\section{Revision of product sector regulatory data requirements}

The efficient uptake of 'Three Rs best practices', to achieve practical, near-term reduction in animal use in product sectors (pesticides, industrial chemicals, medicinal products, etc), is hampered by complex and highly regionalised regulatory frameworks and data requirements. Progress requires a sector-specific and region-specific approach, and often upwards of two years of detailed scientific negotiations with regulators, industry and other stakeholders are necessary to achieve a revised regulation that fulfils the objectives of: a) adopting all available OECD Three $\mathrm{R}_{\mathrm{s}}$ test guidelines and guidance; b) providing flexibility to enable the use of the most efficient testing strategies to reduce animal use to the greatest possible extent without compromising human health or environmental protection; and c) laying the groundwork for a transition toward a future adverse outcome pathway (AOP)-based testing and risk assessment paradigm (6).

\section{Pesticides}

Today, testing to meet regulatory requirements for a new pesticide active ingredient can consume more than 10,000 rodents, rabbits, fish, birds, dogs and other animals, in dozens of separate toxicity and ecotoxicity studies. Animal testing is also carried out on all finished products, and is often 


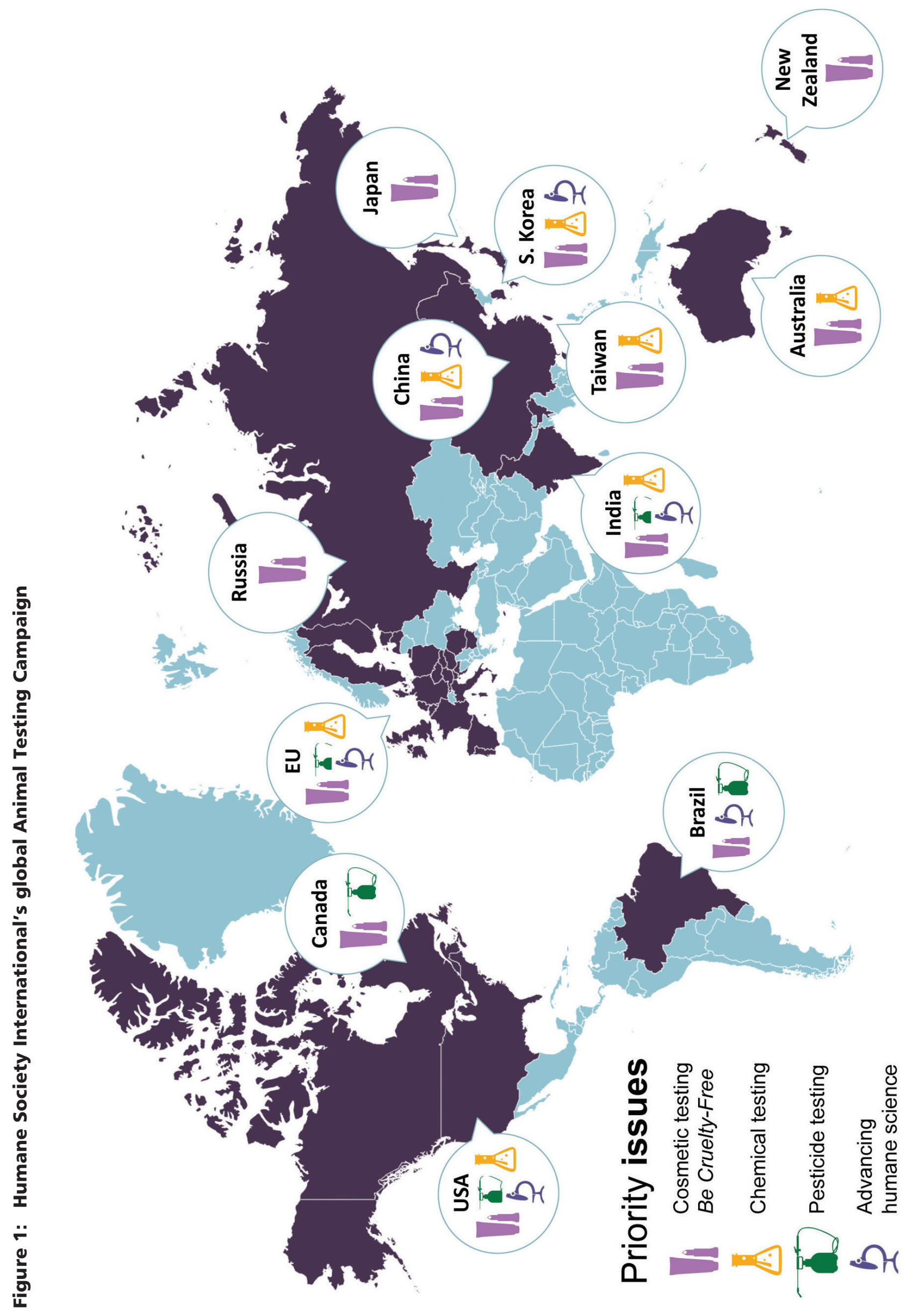


Figure 2: Be Cruelty-Free national advertising campaign in New Zealand
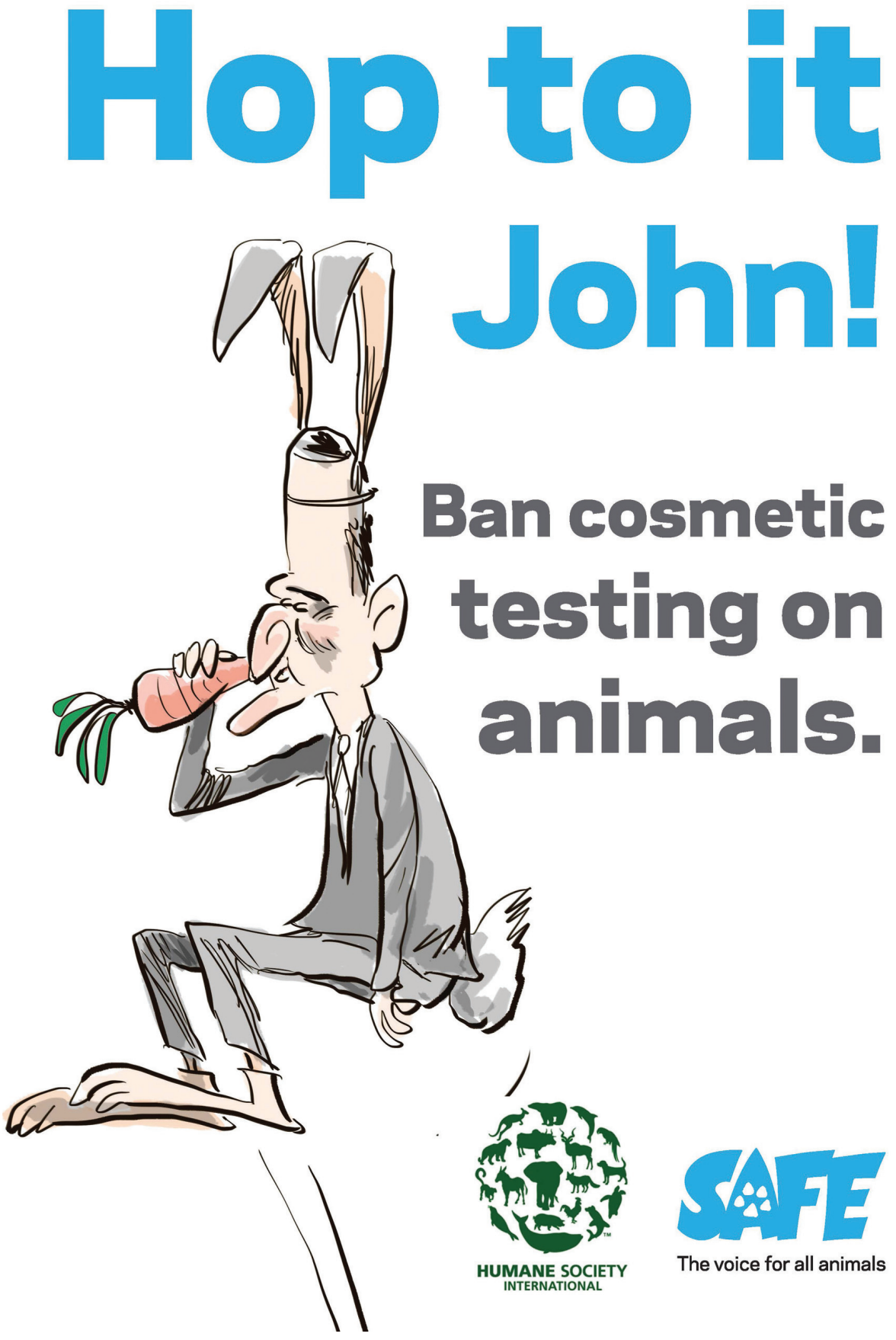

required for the re-registration of existing active ingredients. Overt redundancies abound, including, for some endpoints, the requirement for the same study via multiple exposure routes (e.g. acute, subacute and subchronic testing via oral and/or dermal and/or inhalation routes), or in more than one species (e.g. subchronic and chronic testing in rodents and dogs, prenatal developmental toxicity in rodents and rabbits, carcinogenicity in rats and mice, fish acute studies in two or more species, etc).
Between 2010 and 2013, HSI and its partners undertook to influence technical and political negotiations around the scheduled revision of European directives for plant protection and biocidal products (i.e. agricultural and non-agricultural pesticides, respectively). Working from regulatory proposals drafted by the European Commission, HSI identified more than 100 opportunities to revise toxicological data requirements for biocides, in order to remove redundancies and incorporate new OECD Three Rs guideline methods and other 
innovative testing strategies. In the case of acute toxicity, HSI collaborated with the European Centre for the Validation of Alternative Methods (ECVAM) to carry out a new data analysis to objectively examine the regulatory value of testing via multiple exposure routes (7).

The political process involved multiple rounds of negotiations with Commission scientists, Parliamentary rapporteurs and Member State regulators. Ultimately, more than 80 amendments put forward by HSI were adopted in the new EU Biocidal Products Regulation (8), including:

- deletion of the dog chronic toxicity study;

- uptake of the new OECD Extended One-generation Reproductive Toxicity Study;

- downgrading several second route/species study types to conditional requirements;

- a requirement to consider combining two or more endpoints within the framework of a single repeated-dose toxicity study (e.g. the addition of neuro/immuno endpoints and/or the presence of micronuclei for genotoxicity assessment); and

- broad provision for 'classification by calculation' for formulations and finished products.

These and other measures, when taken together, represent possibly the largest one-time reduction in in vivo data requirements in a regulated product sector, and are the bases on which HSI was awarded the 2012 Lush Prize for lobbying (lushprize.org). A number of similar measures have also been taken up in new EU regulations setting out data requirements for plant protection products $(9$, 10). Since achieving these regulatory precedents in the EU, HSI has begun active outreach to pesticide regulators in Canada, India, Brazil and the USA, with an eye to extending these Three Rs best practices globally, and already some progress has been achieved (11).

\section{Chemicals}

In addition to advocating global uptake of Three $\mathrm{Rs}_{\mathrm{s}}$ best practices within the pesticide sector, HSI is also actively pressing the EU to revise data requirements under the $\mathrm{REACH}$ chemical regulations (12). Millions of animals could be spared suffering and death, if EU chemical regulators would simply accept the same Three Rs best practices that have already been taken up by their pesticide regulatory counterparts, for the tens of thousands of substances that fall within the scope of REACH. Not only is this the responsible and humane option, it is also a legal requirement under REACH that animal testing be carried out only as a last resort (Article 25.1), and that data requirements be updated "as soon as possible" and "with a view to reducing testing on vertebrate animals" (Article 13.2). Yet, despite this mandate, and that more than 18 months have passed since HSI presented its proposal to update REACH data requirements, meaningful action on the part of the European Commission remains conspicuously absent. European progress in this area is also consequential for other countries that have chosen to emulate $\mathrm{REACH}$ as a model for their own domestic chemical regulations (e.g. China REACH, and K-REACH in South Korea). HSI and its regional partners are actively working to influence new and revised chemical regulations, particularly in the Asia-Pacific region, to ensure that contemporary Three $\mathrm{R}_{\mathrm{s}}$ best practices are taken up in lieu of alignment with the now outdated EU REACH regulations.

\section{Advancing humane science}

\section{AXLR8 and the Human Toxicology Project}

The view that conventional animal models of human safety and efficacy are time-intensive and resource-intensive, restrictive in the number of substances that can be tested, of limited use in providing mechanistic understanding, and of even more limited relevance to human biology, has gone from being dismissed as anti-vivisectionist rhetoric, to being embraced as a compelling driver for a fundamental paradigm shift in toxicology (13). The US National Academy of Sciences 2007 report (14) has not only inspired a number of regional and multinational research efforts aimed at advancing '21st century toxicology' - from the US interagency Tox21 collaboration (epa.gov/ncct/tox21), to the European SEURAT-1 project (seurat-1.eu) and the OECD global initiative to map AOPs (bit.ly/1hFUYl6) — it has also shifted the discussion from whether animal testing can be replaced, to how quickly this goal can be achieved (15).

Leading universities, research institutes and companies have joined HSI under the EU 7th Framework project, AXLR8 (axlr8.eu), to develop a roadmap to guide 21st century toxicology-related EU research investment under the forthcoming funding programme, Horizon 2020 (16). In addition, through the Human Toxicology Project Consortium (htpconsortium.org), HSI, HSUS and corporate partners are working hand-in-hand on a global basis, to dramatically increase public and private research funding in this important area (Figure 1). HSI also serves on a number of governmental expert and stakeholder advisory bodies, including at European and OECD levels, where we contribute to high-level discussions regarding processes for the validation and regulatory acceptance of novel testing tools. HSI is honoured also to 
have two of its scientists serving as judges for the Lush Prize, to help promote and award tangible progress toward animal replacement.

\section{Disease models in biomedical research}

In contrast to the relatively rapid shift under way in toxicology, the inertia in the wider biomedical research community — which accounts for more than $80 \%$ of all animal use for scientific purposes - is more pronounced. Intolerance persists of questions, or criticisms, regarding the validity and value of animal models of human disease, despite a scant and painstakingly slow rate of progress in crucial disease areas and an ever-growing body of published evidence pointing to the need for a shift in research paradigm (17-22). As noted by the former US National Institutes of Health director, Elias Zerhouni:

"We have moved away from studying human disease in humans... We all drank the Kool-Aid on that one, me included... The problem is that it hasn't worked, and it's time we stopped dancing around the problem... We need to refocus and adapt new methodologies for use in humans to understand disease biology in humans." (23)

In the interests of stimulating further constructive debate within the biomedical research community, HSI and HSUS scientists have begun contributing scholarly reviews in several disease areas, including asthma (24), Alzheimer's disease, Parkinson's disease, and Amyotrophic Lateral Sclerosis (K. Willett, personal communication, 01.11.13). Recently, HSI launched a grant programme to sponsor reviews and publications by independent academic scientists that critically examine animal models in a particular disease area, and propose a forwardlooking scientific 'roadmap' for the disease area based on 21st century human biology-based (nonanimal) tools. Interventions from HSI in political negotiations for Horizon 2020 have already achieved new directional language to better-focus future EU health research funding on human-relevant approaches (in lieu of more genetically-modified mice), with emphasis on AOP discovery and bioinformatics, expanded development of human biology-based cellular and computational tools, and funding for new research infrastructures such as high-throughput in vitro screening and supercomputing capacity. HSI will provide funding for its disease model grant recipients to present their publications at key scientific conferences worldwide, and will organise high-level briefings for national public and private research funding bodies, with an eye to shifting resources away from failing models in the interests of more-humane investments and better returns for human health.

\section{Conclusions}

Investment in the science needed to replace the use of animals in testing and research is much more than a political objective driven by ethical considerations; it is an opportunity to improve our fundamental understanding of human biology as a means of achieving optimal health and being able to effectively treat - and ideally prevent - disease. In the interim, incremental, yet significant, reductions in animal use can be achieved through more-robust application of established Three $\mathrm{R}_{\mathrm{s}}$ best practices across regulated product sectors globally, laying the groundwork for a more substantial methodological shift over the longer-term. In emerging economies, an initial focus on cosmetics provides an effective gateway through which to inform and engage the public and policymakers and put the animal testing issue on the government agenda.

\section{Acknowledgements}

HSI would like to thank Lush Cosmetics for its generous financial and campaign support for $B e$ Cruelty-Free, and all our regional Be Cruelty-Free partners around the globe for their collaboration. AXLR8 is a coordination and support project funded by the European Commission under the 7th European Framework Programme on Research and Innovation (Grant No. 241958). All work on Horizon 2020 political negotiations was carried out by using grant funds generously provided by the World Society for the Protection of Animals. HSI would also like to thank WSPA for funding a portion of its disease models initiative.

\section{References}

1. EU SME Centre (2012). Importing Cosmetic Products into China, 9pp. Beijing, China: EU SME Centre. Available at: http://www.ccilc.pt/sites/ default/files/docs/importacao_de_cosmeticos_na_ china_en_eusmecenter.pdf (Accessed 15.11.13).

2. Risk \& Policy Analysis Limited (2004). Comparative Study on Cosmetics Legislation in the EU and other Principal Markets with Special Attention to so-called Borderline Products, 142pp. Brussels, Belgium: European Commission, DG Enterprise. Available at: http://ec.europa.eu/enterprise/ newsroom/cf/_getdocument.cfm?doc_id $=4557$ (Accessed 15.11.13).

3. Jyothi Datta, P.T. (2013). India, first South Asian nation to ban cosmetics testing on animals. [The Hindu Business Line, 29 June 2013.] Available at: http://www.thehindubusinessline.com/economy/ india-first-south-asian-nation-to-ban-cosmeticstesting-on-animals/article4862986.ece (Accessed 01.11.13).

4. Agência Nacional de Vigilância Sanitária (2012). Guia para Avaliação de Segurança de Produtos 
Cosméticos. Brasília, Brazil: ANVISA.

5. Humane Society International (2013). Global Polls Reveal Consumers Worldwide Want an End to Animal Testing for Cosmetics. Available at: http:// www.hsi.org/news/news/2013/03/global_cosmetics _polling_031114.html (Accessed 01.11.13).

6. Mackay, C., Davies, M., Summerfield, V. \& Maxwell, G. (2013). From pathways to people: Applying the adverse outcome pathway (AOP) for skin sensitization to risk assessment. ALTEX 30, 473-486.

7. Seidle, T., Prieto, P. \& Bulgheroni, A. (2011). Examining the regulatory value of multi-route mammalian acute systemic toxicity studies. ALTEX 28, 95-102.

8. Anon. (2012). Regulation (EU) No 528/2013 of the European Parliament and of the Council of 22 May 2012 concerning the making available on the market and use of biocidal products (2012). Official Journal of the European Union L167, 26.06.2012, $1-121$.

9. Anon. (2013). Commission Regulation (EU) No 283/ 2013 of 1 March 2013 setting out the data requirements for active substances, in accordance with Regulation (EC) No 1107/2009 of the European Parliament and of the Council concerning the placing of plant protection products on the market. Official Journal of the European Union L93, 03.04.2013, 1-83.

10. Anon. (2013). Commission Regulation (EU) No 284/ 2013 of 1 March 2013 setting out the data requirements for plant protection products, in accordance with Regulation (EC) No 1107/2009 of the European Parliament and of the Council concerning the placing of plant protection products on the market. Official Journal of the European Union L93, 03.04.2013, 85-152.

11. HSI (2013). EPA's reductions in pesticide animal testing requirements welcomed [Press release, 21.05.2012]. Washington DC, USA: The Humane Society of the United States. Available at: http:// www.humanesociety.org/news/press_releases/2012/ 05/epas_reductions_pesticide_052112.html\#.Unb MAWRDuYA (Accessed 01.11.13).

12. Anon. (2006). Regulation (EC) No $1907 / 2006$ of the European Parliament and of the Council of 18 December 2006 concerning the Registration, Evaluation, Authorisation and Restriction of Chemicals (REACH), establishing a European Chemicals Agency, amending Directive 1999/45/EC and repealing Council Regulation (EEC) No 793/93 and Commission Regulation (EC) No $1488 / 94$ as well as Council Directive 76/769/EEC and Commission Directives 91/155/EEC, 93/67/EEC, 93/105/EC and 2000/21/EC. Official Journal of the European Union L136, 25.05.2007, 3-280.

13. Collins, F.S. (2011). Reengineering translational science: The time is right. Science Translational Medicine 3, 1-6.

14. US National Research Council Committee on
Toxicity Testing and Assessment of Environmental Agents (2007). Toxicity Testing in the 21st Century: A Vision and a Strategy, 216pp. Washington DC, USA: National Academies Press.

15. Weise, E. (2008). Three US agencies aim to end animal testing. [USA Today, 14 Feb 2008.] Available at: http://usatoday30.usatoday.com/tech/science/200802-14-animal-tests_N.htm (Accessed 01.11.13).

16. Langley, G. (2012). Advancing Safety Science and Health Research with Innovative, Non-animal Tools. London, UK: Humane Society International. Available at: http://www.hsi.org/issues/advancing science/research/horizon2020report.pdf (Accessed 01.11.13).

17. Seok, J., Warren, H.S., Cuenca, A.G., Mindrinos, M.N., Baker, H.V., Xu, W., Richards, D.R., McDonaldSmith, G.P., Gao, H., Hennessy, L., Finnerty, C.C., López, C.M., Honari, S., Moore, E.E., Minei, J.P., Cuschieri, J., Bankey, P.E., Johnson, J.L., Sperry, J., Nathens, A.B., Billiar, T.R., West, M.A., Jeschke, M.G., Klein, M.B., Gamelli, R.L., Gibran, N.S., Brownstein, B.H., Miller-Graziano, C., Calvano, S.E., Mason, P.H., Cobb, J.P., Rahme, L.G., Lowry, S.F., Maier, R.V., Moldawer, L.L., Herndon, D.N., Davis, R.W., Xiao, W., Tompkins, R.G.; Inflammation and Host Response to Injury, Large Scale Collaborative Research Program (2013). Genomic responses in mouse models poorly mimic human inflammatory diseases. Proceedings of the National Academy of Sciences of the USA 110, 3507-3012.

18. Lamontagne, F., Briel, M., Duffett, M., FoxRobichaud, A., Cook, D.J., Guyatt, G., Lesur, O. \& Meade, M.O. (2010). Systematic review of reviews including animal studies addressing therapeutic interventions for sepsis. Critical Care Medicine 38, 2401-2408.

19. Sena, E.S., van der Worp, H.B., Bath, P.M.W., Howells, D.W. \& Macleod, M.R. (2010). Publication bias in reports of animal stroke studies leads to major overstatement of efficacy. PLoS Biology 8, e1000344.

20. Sriram, S. \& Steiner, I. (2005). Experimental allergic encephalomyelitis: A misleading model of multiple sclerosis. Annals of Neurology 58, 939-945.

21. Ehrnhoefer, D.E., Butland, S.L., Pouladi, M.A. \& Hayden, M.R. (2009). Mouse models of Huntington disease: Variations on a theme. Disease Models \& Mechanisms 2, 123-129.

22. Cryan, J.F. \& Mombereau, C. (2004). In search of a depressed mouse: Utility of models for studying depression-related behavior in genetically modified mice. Molecular Psychiatry 9, 326-357.

23. McManus, R. (2013). Ex-director Zerhouni surveys value of NIH research. NIH Record LXV. Available at: http://nihrecord.od.nih.gov/newsletters/2013/ 06_21_2013/story1.htm (Accessed 01.11.13).

24. Buckland, G.L. (2011). Harnessing opportunities in non-animal asthma research for a 21st-century science. Drug Discovery Today 16, 914-927. 